\title{
Efficacy of Taurolidine Irrigation in Primary Total Knee Arthroplasty
}

\author{
Young Ha Woo, MD, Ju Seon Jeong, MD, Ok Geol Kim, MD, and In Seung Lee, MD \\ Department of Orthopedic Surgery, Busan Bumin Hospital, Busan, Korea
}

\begin{abstract}
Purpose: Taurolidine is an antimicrobial agent that was originally used in the local treatment of peritonitis. The aim of this study was to evaluate the efficacy of taurolidine irrigation in primary total knee arthroplasty (TKA).

Materials and Methods: All patients who underwent TKA at our institute from January 2015 to March 2017 were eligible. There were 300 patients in the taurolidine irrigation group and 300 patients in the control group. The patients in the taurolidine irrigation group were irrigated after implantation with a mix of $250 \mathrm{~mL}$ of taurolidine and $750 \mathrm{~mL}$ of normal saline. The patients in the control group were not irrigated after implantation. We compared postoperative C-reactive protein (CRP), erythrocyte sedimentation rate (ESR), and infection rate between groups.

Results: The taurolidine irrigation group had a significantly lower CRP $(5.39 \mathrm{mg} / \mathrm{dL}$ vs. $7.55 \mathrm{mg} / \mathrm{dL} ; \mathrm{p}<0.001)$ and ESR $(53.21 \mathrm{~mm} / \mathrm{hr}$ vs. $58.74 \mathrm{~mm} /$ $\mathrm{hr} ; \mathrm{p}=0.003$ ) on postoperative day 3 after TKA, as compared with the control group. However, there was no difference between the two groups on postoperative days 6,13 , and 20. Periprosthetic joint infection occurred in one patient in the taurolidine irrigation group.

Conclusions: We believe that it is not necessary to use taurolidine for patients who undergo primary TKA.
\end{abstract}

Keywords: Knee, Infection, Arthroplasty, Taurolidine, C-reactive protein

\section{Introduction}

Total knee arthroplasty (TKA) is one of the most effective treatments of end-stage knee arthritis. The number of patients who will likely require TKA is expected to increase substantially in the near future due to the growing aging population ${ }^{1)}$. Outcomes following TKA are excellent in the majority of patients who undergo the procedure. Perhaps the most challenging complication following TKA is periprosthetic joint infection. Several methods and studies have been conducted to prevent infection following TKA. The use of laminar flow rooms, proper skin preparation,

Received July 24, 2017; Revised (1st) September 8, 2017;

(2nd) September 19, 2017; (3rd) September 21, 2017;

(4th) October 9, 2017; Accepted October 30, 2017

Correspondence to: Ju Seon Jeong, MD

Department of Orthopedic Surgery, Bumin Hospital, 59 Mandeok-daero, Buk-gu, Busan 46555, Korea

Tel: +82-51-330-3082, Fax: +82-51-330-3075

E-mail: mdjjs78@naver.com

This is an Open Access article distributed under the terms of the Creative Commons Attribution Non-Commercial License (http://creativecommons.org/licenses/by-nc/4.0/) which permits unrestricted non-commercial use, distribution, and reproduction in any medium, provided the original work is properly cited. limits on operating room traffic, administration of appropriate antibiotics prior to surgical incision, and the use of various wound closure techniques can help to decrease infection rates ${ }^{2)}$.

Taurolidine is an antimicrobial agent often used in experimental and clinical studies to prevent intra-abdominal adhesion formation and sepsis ${ }^{3)}$. It was initially used for its anti-inflammatory and antimicrobial properties in the treatment of surgical and wound infections, as well as for preventing infections stemming from the use of central venous catheters ${ }^{4-6}$. Taurolidine is also known to reduce thrombus weight ${ }^{3)}$. Furthermore, it seems to have a direct effect on tumor cells with a consecutive inhibition of cell growth ${ }^{7-9)}$. However, there are few studies on the effects of taurolidine in orthopedic surgery. In particular, there has been no study conducted regarding whether taurolidine can reduce the risk of infection after TKA.

The purpose of the current study was to determine whether taurolidine could affect infection rates and inflammatory marker changes after TKA.

\section{Materials and Methods}

A total of 600 patients, (300 in the taurolidine irrigation group 
and 300 in the control group) who had been treated by a unilateral primary cemented TKA due to primary osteoarthritis of the knee in the period from January 2015 to March 2017, were retrospectively included in the study (Fig. 1). We used taurolidine until May 2016 and have not used it since in TKA patients. The taurolidine irrigation group was irrigated after implantation with a mix of $250 \mathrm{~mL}$ of taurolidine (taurolidine injection $2 \%$, Samjin, Seoul, Korea) and $750 \mathrm{~mL}$ of normal saline. The control group was not irrigated after implantation. Inclusion criteria were patients with grade 3 or 4 osteoarthritis of the knee. Exclusion criteria were the absence of written informed consent, bilateral arthroplasties, complicated primary TKA with previous osteotomy, simultaneous fracture fixation, implant removal or bone grafting, thromboembolic diseases, presence of clotting disorder or current treatment with an antiplatelet agent, renal disease, and/or a history of allergy to taurolidine. All arthroplasties were performed through the medial parapatellar approach with the use of a tourniquet, a posterior-stabilized implant, a bone plug in the intramedullary canal, cementation, hemostasis with a tourniquet on, a compression bandage, suction pressure drainage for 48 hours, and a foot pump for deep vein thrombosis prophylaxis. All of the patients were given three doses of first-generation cephalosporin (one within 30 minutes before the procedure, and two doses at 12-hour intervals postoperatively). The primary outcome measures were erythrocyte sedimentation rate (ESR) and C-reactive protein (CRP). We evaluated the levels of CRP and ESR 3, 6, 13, and 20 days postoperatively. Previous studies have reported that plasma CRP levels in TKA patients increase rapidly after operation reaching maximum values within 2-3 days, after which they decrease rapidly ${ }^{10-14)}$. Secondary outcome measures included periprosthetic joint infection.
Differences between the two groups were analyzed with the Student $t$-test for continuous variables and Pearson chi-square test or Fisher exact test for categorical variables. The mean changes in each group were analyzed with the independent $t$-test. Statistical analyses were performed with the IBM SPSS ver. 20.0 (IBM Co., Armonk, NY, USA). $\mathrm{p}<0.05$ were considered statistically significant.

\section{Results}

The patients' mean age was 70.2 years in the taurolidine irrigation group and 71.2 years in the control group. There were no other significant differences between the two groups in terms of the considered baseline characteristics, including body weight, height, body mass index, and operation time (Table 1). On the outcome measures, the taurolidine irrigation group had a significantly lower CRP (5.39 mg/dL vs. $7.55 \mathrm{mg} / \mathrm{dL}$; p<0.001) and ESR ( $53.21 \mathrm{~mm} / \mathrm{hr}$ vs. $58.74 \mathrm{~mm} / \mathrm{hr} ; \mathrm{p}=0.003)$ on postoperative day

Table 1. Baseline Characteristics

\begin{tabular}{lccc}
\hline \multicolumn{1}{c}{ Characteristic } & $\begin{array}{c}\text { Taurolidine } \\
\text { group }(\mathrm{n}=300)\end{array}$ & $\begin{array}{c}\text { Control } \\
\text { group }(\mathrm{n}=300)\end{array}$ & p-value \\
\hline Age (yr) & $70.2 \pm 8$ & $71.2 \pm 8$ & 0.070 \\
Sex (F) & 68.4 & 69.1 & 0.693 \\
Body weight $(\mathrm{kg})$ & $66.1 \pm 11.7$ & $67.3 \pm 11.5$ & 0.502 \\
Height $(\mathrm{m})$ & $1.55 \pm 0.08$ & $1.56 \pm 0.09$ & 0.902 \\
BMI $\left(\mathrm{kg} / \mathrm{m}^{2}\right)$ & $26.6 \pm 4.1$ & $27.3 \pm 4.3$ & 0.289 \\
Operation time $(\mathrm{min})$ & $91 \pm 15$ & $92 \pm 12$ & 0.494 \\
\hline
\end{tabular}

Values are presented as mean \pm standard deviation or percentage. BMI: body mass index.
TKA: January 2015 to March $2017(n=1,048)$

\begin{tabular}{c}
$\begin{array}{l}\text { January } 2015 \text { to May 2016: taurolidine was used } \\
(\mathrm{n}=730) \\
\text { June } 2016 \text { to March 2017: taurolidine was not used } \\
(\mathrm{n}=318)\end{array}$ \\
\hline
\end{tabular}

Excluded

Bilateral TKA $(n=98)$

Complex TKA $(\mathrm{n}=24)$

Simultaneous fracture fixation $(n=11)$

Renal disease $(n=9)$

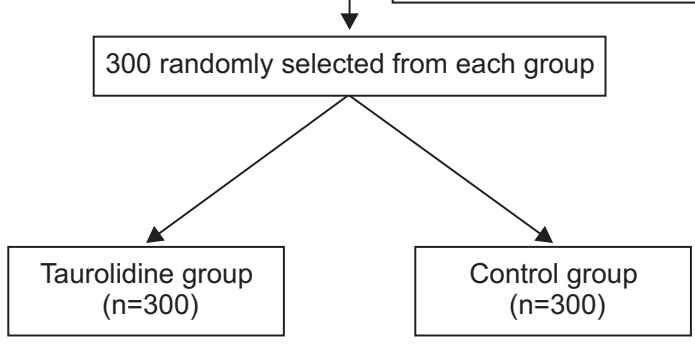

Fig. 1. Consolidated Standards of Reporting Trials (CONSORT) flow diagram of patients. TKA: total knee arthroplasty. 
Table 2. Outcome Measures

\begin{tabular}{cccc}
\hline Variable & $\begin{array}{c}\text { Taurolidine } \\
\text { group }(\mathrm{n}=300)\end{array}$ & $\begin{array}{c}\text { Control } \\
\text { group }(\mathrm{n}=300)\end{array}$ & p-value \\
\hline CRP $(\mathrm{mg} / \mathrm{dL})$ & & & \\
POD 3 & $5.39 \pm 3.57$ & $7.55 \pm 3.94$ & $<0.001$ \\
POD 6 & $2.81 \pm 2.41$ & $2.60 \pm 2.32$ & 0.29 \\
POD 13 & $0.96 \pm 1.29$ & $0.90 \pm 1.73$ & 0.66 \\
POD 20 & $0.82 \pm 0.94$ & $0.90 \pm 1.73$ & 0.79 \\
ESR (mm/hr) & & & \\
POD 3 & $53.21 \pm 20.22$ & $58.74 \pm 24.81$ & 0.003 \\
POD 6 & $59.17 \pm 26.39$ & $58.11 \pm 21.96$ & 0.59 \\
POD 13 & $45.55 \pm 21.43$ & $41.36 \pm 19.84$ & 0.01 \\
POD 20 & $42.68 \pm 22.99$ & $44.19 \pm 24.39$ & 0.77 \\
Infection & 1 & 0 & 0.32 \\
\hline
\end{tabular}

Values are presented as mean \pm standard deviation. CRP: C-reactive protein, POD: postoperative day, ESR: erythrocyte sedimentation rate.

3 in primary TKA. However, the taurolidine irrigation was not helpful to reduce CRP and ESR on postoperative days 6, 13, and 20. Periprosthetic joint infection occurred in only one patient in the taurolidine irrigation group, showing no statistical significance (Table 2).

\section{Discussion}

Infection is one of the most devastating complications following TKA, occurring in $1.55 \%$ of patients with Medicare within the first two postoperative years, and demonstrating a further incidence of $0.46 \%$ between postoperative years two and $\operatorname{ten}^{15)}$. In our study, one patient in the taurolidine group had a periprosthetic joint infection and there was no infection in the control group.

The diagnosis of infection after arthroplasty is quite difficult. Clinical, radiological and scintillographic findings and laboratory determinations of plasma CRP levels and ESRs are valuable in the diagnosis of infection and in the selection of appropriate treatment. Postoperatively, studies have proven the benefits of using CRP and ESR in the diagnosis of periprosthetic joint infection ${ }^{16)}$. Serological inflammatory markers, specifically ESR and CRP, are often used as initial tests, even when there is a low suspicion of periprosthetic joint infection ${ }^{17)}$. They are also commonly used in monitoring patient responses to therapy since they are inexpensive, non-invasive, and widely available.

Taurolidine was synthesized in the 1970s and was originally used as an antibiotic in the prophylactic treatment of intraperi- toneal bacterial infections in patients with established peritonitis $^{18,19)}$. Intraoperative and early postoperative local application of taurolidine, in addition to appropriate surgical treatment and postoperative care, has an important role in the prevention of postoperative septic complications, and has been found to decrease the potential for postoperative mortality ${ }^{20}$. The utility of taurolidine as an antitumor agent has been investigated extensively recently ${ }^{21)}$.

Taurolidine [bis (1,1-dioxo-perhydro-1, 2, 4-thiadiazinyl-4) methane] is a broad spectrum, non-antibiotic antimicrobial agent derived chemically from the aminosulfonic acid, taurine. The antimicrobial activity of taurolidine is considered to be due to the delivery of biologically active methylol taurinamide components that react via methylene iminium ions with cell wall constituents of bacteria ${ }^{22)}$.

Taurolidine has a unique spectrum of antimicrobial activity, including gram-positive and gram-negative bacteria and fungi ${ }^{23,24}$. Taurolidine demonstrates a bactericidal mode of action against a wide range of bacterial species, such as Staphylococcus aureus (S. aureus), Staphylococcus epidermidis (S. epidermidis), Bacteroides fragilis, and group C Streptococci ${ }^{25,26)}$. Taurolidine has been used for a long time in abdominal infections, in lung infections, and in dentistry ${ }^{27}$. The most common organisms that cause infection after TKA are S. aureus, S. epidermidis, and Streptococcus species. Therefore, we supposed that taurolidine may contribute some to reducing the risk of infection after TKA.

Our present study showed that taurolidine irrigation was effective in lowering CRP (5.39 mg/dL vs. $7.55 \mathrm{mg} / \mathrm{dL}$ ) and ESR (53.21 $\mathrm{mm} / \mathrm{hr}$ vs. $58.74 \mathrm{~mm} / \mathrm{hr}$ ) on postoperative day 3 in primary TKA. This suggests that taurolidine irrigation is effective in lowering inflammation by postoperative day 3 . However, taurolidine irrigation was not helpful to reduce CRP and ESR on postoperative days 6,13 , and 20. Additionally, there was one case of infection in the taurolidine irrigation group, and no case of infection in the control group, showing no statistically significant difference.

Several limitations exist in this study. First, this study included a small number of subjects. Second, this is a retrospective study based on the review of past medical records, so we do not know what information was not recorded. Third, the follow-up period of this study was too short. Finally, there may be multiple causes, which can have complex effects on the CRP level.

\section{Conclusions}

The present study shows that taurolidine irrigation is effective in 
reducing CRP and ESR levels on postoperative day 3 in primary TKA. However, taurolidine irrigation was not helpful to reduce CRP and ESR on postoperative days 6, 13, and 20. Therefore, we believe that it is not necessary to use taurolidine for patients who undergo primary TKA.

\section{Conflict of Interest}

No potential conflict of interest relevant to this article was reported.

\section{References}

1. Kurtz S, Ong K, Lau E, Mowat F, Halpern M. Projections of primary and revision hip and knee arthroplasty in the United States from 2005 to 2030. J Bone Joint Surg Am. 2007;89: 780-5.

2. Daines BK, Dennis DA, Amann S. Infection prevention in total knee arthroplasty. J Am Acad Orthop Surg. 2015;23: 356-64.

3. Kaptanoglu L, Kucuk HF, Colak E, Kurt N, Bingul SM, Akyol H, Torlak OA, Yazici F. The effect of taurolidine on experimental thrombus formation. Eur J Pharmacol. 2008;578:23841.

4. Traub WH, Leonhard B, Bauer D. Taurolidine: in vitro activity against multiple-antibiotic-resistant, nosocomially significant clinical isolates of Staphylococcus aureus, Enterococcus faecium, and diverse Enterobacteriaceae. Chemotherapy. 1993;39:322-30.

5. Willatts SM, Radford S, Leitermann M. Effect of the antiendotoxic agent, taurolidine, in the treatment of sepsis syndrome: a placebo-controlled, double-blind trial. Crit Care Med. 1995;23:1033-9.

6. Koldehoff M, Zakrzewski JL. Taurolidine is effective in the treatment of central venous catheter-related bloodstream infections in cancer patients. Int J Antimicrob Agents. 2004; 24:491-5.

7. McCourt M, Wang JH, Sookhai S, Redmond HP. Taurolidine inhibits tumor cell growth in vitro and in vivo. Ann Surg Oncol. 2000;7:685-91.

8. Calabresi P, Goulette FA, Darnowski JW. Taurolidine: cytotoxic and mechanistic evaluation of a novel antineoplastic agent. Cancer Res. 2001;61:6816-21.

9. Da Costa ML, Redmond HP, Bouchier-Hayes DJ. Taurolidine improves survival by abrogating the accelerated development and proliferation of solid tumors and development of organ metastases from circulating tumor cells released following surgery. J Surg Res. 2001;101:111-9.

10. Choudhry RR, Rice RP, Triffitt PD, Harper WM, Gregg PJ. Plasma viscosity and C-reactive protein after total hip and knee arthroplasty. J Bone Joint Surg Br. 1992;74:523-4.

11. Niskanen RO, Korkala O, Pammo H. Serum C-reactive protein levels after total hip and knee arthroplasty. J Bone Joint Surg Br. 1996;78:431-3.

12. Larsson S, Thelander U, Friberg S. C-reactive protein (CRP) levels after elective orthopedic surgery. Clin Orthop Relat Res. 1992;(275):237-42.

13. Aalto K, Osterman K, Peltola H, Rasanen J. Changes in erythrocyte sedimentation rate and C-reactive protein after total hip arthroplasty. Clin Orthop Relat Res. 1984;(184):11820.

14. White J, Kelly M, Dunsmuir R. C-reactive protein level after total hip and total knee replacement. J Bone Joint Surg Br. 1998;80:909-11.

15. Kurtz SM, Ong KL, Lau E, Bozic KJ, Berry D, Parvizi J. Prosthetic joint infection risk after TKA in the Medicare population. Clin Orthop Relat Res. 2010;468:52-6.

16. Pfitzner T, Krocker D, Perka C, Matziolis G. C-reactive protein: an independent risk factor for the development of infection after primary arthroplasty. Orthopade. 2008;37:111620.

17. Della Valle C, Parvizi J, Bauer TW, Dicesare PE, Evans RP, Segreti J, Spangehl M, Watters WC 3rd, Keith M, Turkelson CM, Wies JL, Sluka P, Hitchcock K; American Academy of Orthopaedic Surgeons. Diagnosis of periprosthetic joint infections of the hip and knee. J Am Acad Orthop Surg. 2010; 18:760-70.

18. Browne MK, Leslie GB, Pfirrman RW, Brodhage $H$. The in vitro and in vivo activity of taurolin against anaerobic pathogenic organisms. Surg Gynecol Obstet. 1977;145:842-6.

19. Knight BI, Skellern GG, Smail GA, Browne MK, Pfirrmann RW. NMR studies and GC analysis of the antibacterial agent taurolidine. J Pharm Sci. 1983;72:705-7.

20. Popovic M, Dugalni D, Milicevic M, Petrovic M, Zuvela M, Knezevic S, Jankovic Z. Use of taurolin in the prevention of septic complications in emergency abdominal surgery. Acta Chir Iugosl. 1991;38:23-33.

21. Jacobi CA, Menenakos C, Braumann C. Taurolidine: a new drug with anti-tumor and anti-angiogenic effects. Anticancer Drugs. 2005;16:917-21.

22. Gidley MJ, Sanders JK. Mechanisms of antibacterial formaldehyde delivery from noxythiolin and other 'masked-form- 


\section{Woo et al. Efficacy of Taurolidine Irrigation in Total Knee Arthroplasty}

aldehyde' compounds. J Pharm Pharmacol. 1983;35:712-7.

23. Browne MK, Leslie GB, Pfirrmann RW. Taurolin, a new chemotherapeutic agent. J Appl Bacteriol. 1976;41:363-8.

24. Brearley S, George RH. The rate of antimicrobial action of noxythiolin and taurolin. J Hosp Infect. 1980;1:201-9.

25. Jones DS, Gorman SP, McCafferty DF, Woolfson AD. The effects of three non-antibiotic, antimicrobial agents on the surface hydrophobicity of certain micro-organisms evalu- ated by different methods. J Appl Bacteriol. 1991;71:218-27.

26. Bieselt R. Surgical therapy of pleural empyema with tauroline. Langenbecks Arch Chir. 1997;382(4 Suppl 1):S42-6.

27. Zimmermann M, Preac-Mursic V. In vitro activity of taurolidine, chlorophenol-camphor-menthol and chlorhexidine against oral pathogenic microorganisms. Arzneimittelforschung. 1992;42:1157-9. 